\section{Variability of mammals}

Variability of Mammals. By A. V. Yablokov. Translated from Russian. Pp. $x v+350$. (Amerind: New Delhi.) $\$ 12.50$.

THIS book deals with an increasingly felt need for a unified approach to the collation of data on population morphology. In the past this has been in the province of geneticists, comparative anatomists, zoogeographers and taxonomists, but now data are collected and required by a far wider spectrum of biologists. In synthesising this review, Professor Yablokov has drawn heavily on data collected by Russian biologists which are not readily available in the west. Useful as that approach is, it inevitably means that field data must be accepted at face value for accuracy of measurement and no allowance made for error; the book does not caution the reader to be on his guard to interpret the facts accordingly. Nevertheless, a great deal of work has yet to be done before a general theory of variability can be advanced, and one must beware of throwing the baby out with the bathwater.

The first part of the book lays the foundations for a discussion of the adaptiveness of variability by using a coefficient of variation of a series of traits as an index of the different ecological conditions encountered by different populations of the same species. Since few distribution curves for given traits correspond to a normal distribution, the best means for expressing differences is a problem yet to be solved by morphologists. The dimensionless coefficient the standard deviation divided by the sample mean and expressed as a percentage) is used throughout the book to compare widely different traits between populations within a species, within a genus, between closely related genera, between subfamilies and within an order. The result of the author's examination of traits in the Pinnipedia indicates that the coefficient of variation between two populations may be significantly greater than the coefficient of variation for populations from two different subfamilies. Professor Yablokov argues for a rationalisation of the classification of variability in various independent ways such that the processes of evolution of different populations can be directly compared. This is particularly valuable when comparing the variability of natural and experimentally controlled populations and that between populations experiencing clearly distinguished and different environmental conditions.
A heavy, laboured style makes for difficult reading, but this may be a result of the translation. Several line diagrams have insufficient legends and the halftone plates are so badly reproduced as to be almost without value. Nevertheless, the book is a useful starting point for the serious student of population evolution and mammalian - in particular pinnipede biology, and it should fulfil a role in describing the baseline of this important area of biology.

\section{Michael Stoddart}

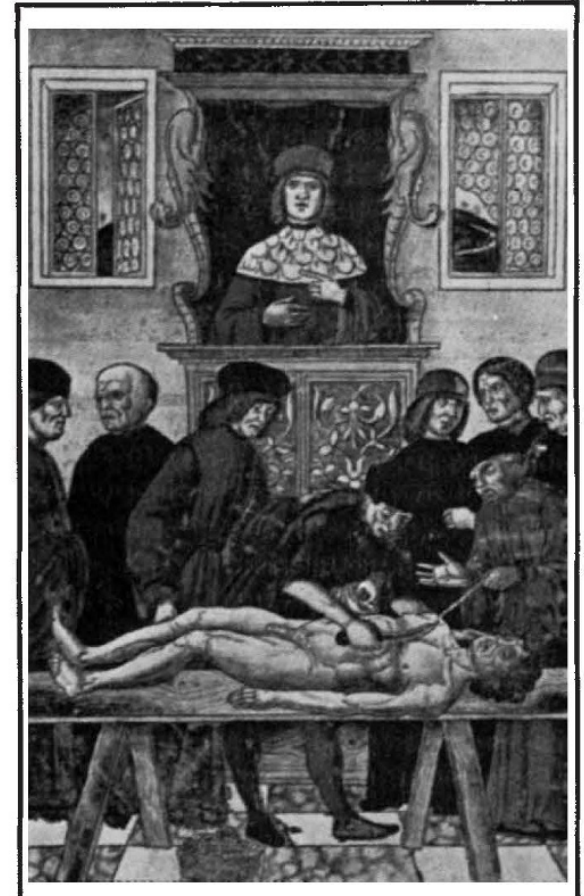

Johannes de Ketham's Fasciculus medicine shows the first printed illustration of a human dissection, attributed by some scholars to the artist Gentile Bellini. Originally published in 1491 in Venice shortly before Copernicus became a medical student in nearby Padua. (Yale Historical Medical Library.) The Nature of Scientific Discovery. (A symposium commemorating the 500th anniversary of the birth of Nicholas Copernicus.) Edited by Owen Gingerich. Po. 616. (Smithsonian Institution Press Washington, DC, June 1975.) \$15.00.

\section{Energetic perspective}

Perspectives on Energy: Issues, Ideas and Environmental Dilemmas. By Lon C. Reudisili and Morris W. Firebaugh. $\mathrm{Pp}$. $\mathrm{xij}+527$. Oxford University: London, New York and Toronto, August 1975.) Boards £6.85; paper $£ 4.00$.

THE objective of the book is to provide clear and concise information on the arguments in America for assuring energy supplies, while not conflicting too much with environmentalists who oppose some of the methods. To pro- duce what the authors believe to be a balanced and representative analysis in areas of controversy, they have made a selection of articles from the recent literature illustrating the energy and environmental dilemmas-reviewing the prospects of fossil and nuclear fuels as energy sources, considering alternative energy possibilities and finally ideas on energy policy for the future.

In each of five chapters the layout is similar-unusual but interesting. Each begins a group of photographs (generally clear and relevant to the subject matter of the papers in the chapter) and each is introduced by a few pages of synopses or commentary.

Glenn T. Seaborg, ex-US Atomic Energy Commission but now in his haven at Berkeley, Californa, repeatedly refers in his foreword to the "readings" in the book. And so the individual papers are, many of them original gems of authority. The book can be picked up and opened almost at random to find a self-sufficient specialist view on some subject of relevance in today's energy world. The 527-page tome, therefore, is really a short daily ration of "sifting and winnowing" to reach an intelligent informed opinion on energy politics assisted by the experts.

Chauncey Starr sets the pace with the "Realities of the Energy Crisis". and M. King Hubbert continues with a "Survey of World Energy Resources". The "Case for Nuclear Energy" is given by B. I. Spinrad followed by half a dozen pages nibbling away at topics like "Reactor Safety," "Disposal of Nuclear Wastes", and "Dilemma on Fission Energy and Pugwash warnings".

The book is rich in clear diagrams and useful tables, indeed worth at least the paperback price for the 24 in the Hubbert paper alone-more than one per page. There are plenty of references given in most of the 40 papers, and, as if that is not enough to keep one going into the small hours there is a suggested reading list at the ends of chapters.

Seaborg opens the debate with worry about a resource crisis (certain metals, food, water, energy) and wonders whether there is sufficient concern for the future. Ruedisili and Firebaugh provide plenty of thought-provoking material and cleverly end the book with Seaborg's answer to his own question on ideas for a "Recycle Society". Scrap would become secondary material but new material would be used rarely and only for top-up of the stock in use. Design for non-obsolescence, communications instead of transport, avoidance of urban sprawl and improvement of the energy situation could all contribute to a better life twenty years from now; that's not far awav. he warns, and we had better get moving.

G. R. Bainbridge 